University of Nebraska - Lincoln

DigitalCommons@University of Nebraska - Lincoln

Faculty Papers and Publications in Animal

Science

Animal Science Department

January 1996

\title{
Variances of Additive and Dominance Genetic Effects for Ovulation and Twinning Rates in a Population Selected for Twinning
}

L. Dale Van Vleck

University of Nebraska-Lincoln, dvan-vleck1@unl.edu

K. E. Gregory

Roman L. Hruska U.S. Meat Animal Research Center, USDA-ARS

Follow this and additional works at: https://digitalcommons.unl.edu/animalscifacpub

Part of the Animal Sciences Commons

Van Vleck, L. Dale and Gregory, K. E., "Variances of Additive and Dominance Genetic Effects for Ovulation and Twinning Rates in a Population Selected for Twinning" (1996). Faculty Papers and Publications in Animal Science. 265.

https://digitalcommons.unl.edu/animalscifacpub/265

This Article is brought to you for free and open access by the Animal Science Department at DigitalCommons@University of Nebraska - Lincoln. It has been accepted for inclusion in Faculty Papers and Publications in Animal Science by an authorized administrator of DigitalCommons@University of Nebraska - Lincoln. 


\title{
Variances of Additive and Dominance Genetic Effects for Ovulation and Twinning Rates in a Population Selected for Twinning
}

\author{
L. D. Van Vleck*,1 and K. E. Gregory'
}

Roman L. Hruska U.S. Meat Animal Research Center, USDA-ARS, *Lincoln, NE 68583-0908 and TClay Center, NE 68933-0166

\begin{abstract}
Estimates of variances due to additive and dominance genetic effects and permanent and temporary environmental effects were obtained for ovulation and twinning rates from a composite population selected for twinning rate. Measures of ovulation rate after 11 mo of age on 2,317 heifers with a total of 19,209 measures were used. Twinning measures were on 1,522 first-parity cows, 1,311 later-parity cows with a total of 3,571 measures, and 1,704 all-parity cows with 5,100 measures. Models included fixed effects of year-season-age at calving for twinning, and yearseason of birth, age in months, and calendar month of measurement for ovulation rate. Four analyses were performed for each sample: combinations of models with and without dominance effects and with and without covariates for fractions of inheritance from the seven foundation groups. Variance components as fractions of phenotypic variance for analysis of all
\end{abstract}

ovulation rate measures were $.076, .000$, and .045 for additive, dominance, and permanent environmental effects with no foundation groups in the model and $.069, .000$, and .050 with foundation groups in the model. For sums of eight measures, the estimates were .287 and .000 for relative variances of additive and dominance effects with groups in the model and .316 and .000 with groups ignored. For twinning rate for first parity, estimates were .126 and .209 for relative variances of additive and dominance effects; for later parities, estimates were .045 and .035 for models including foundation group effects. The results suggest lack of dominance effects in expression of ovulation rate and the possibility of dominance effects for embryo and(or) fetal survival or conception rate because twinning rate is a function of ovulation, conception, and embryo and(or) fetal survival rates.

Key Words: Reproduction, Genetics, Genetic Variance, Beef Cattle

J. Anim. Sci. 1996. 74:1234-1239

\section{Introduction}

A twinning population was established at the U.S. Meat Animal Research Center (MARC) in 1981 to increase economic efficiency of beef production. Results from this project have been reported (Gregory et al., 1990a,b; Echternkamp et al., 1990; Van Vleck et al., 1991a,b) together with a later report of estimates of genetic parameters and genetic trends for ovulation and twinning rates (Van Vleck and Gregory, 1996), which describes the fraction of the nine predominant breeds in the composite as well as phenotypic means for twinning and ovulation rates by year. RodríguezAlmeida et al. (1995) estimated and reviewed estimates of dominance variance for weight traits of beef cattle and yield traits of dairy cattle as well as egg number and quality in poultry. The few estimates

\footnotetext{
$1_{\text {To }}$ whom correspondence should be addressed.

Received May 16, 1995.

Accepted J anuary 29, 1996.
}

were quite variable. A common observation is that traits with low heritability, often reproductive traits, may exhibit heterosis in breed crosses. Twinning and ovulation rate have low heritability, and the twinning population was established from crosses of several breeds. If heterosis is important, then a composite such as the twinning population may show variance due to dominance genetic effects.

A requirement for estimation of dominance genetic variance is that measurements be available for animals with dominance relationships different from zero, such as full sibs with a dominance relationship of .25. Most beef cattle populations, however, have very few full sibs. The nature of a twinning population leads to many full sibs, although with most pairs born at the same time. Therefore, the purpose of this study was to estimate jointly the components of variance due to additive and dominance genetic effects for ovulation and twinning rates from measurements available from the MARC twinning population. Additive by additive and other higher-order genetic effects were not included in the model because of computing limitations 
and because of the difficulty of separating additive and additive by additive genetic variance (Chang et al., 1990; Rodríguez-Almeida et al., 1995).

\section{Materials and Methods}

Data. Measurements of ovulation rate obtained by rectal palpation of corpora lutea beginning after $11 \mathrm{mo}$ of age for approximately eight estrous cycles beginning in the fall of 1984 and measures of number of calves born for cows in the twinning population were available. The population has both fall and spring calving, with heifers bred to first calf at about $30 \mathrm{mo}$ of age. To obtain some idea of sampling variances of estimates of variance components, the ovulation measures were divided into four samples. Measures were in order within cow. The sampling procedure was to assign consecutive acceptable measures in order to the four samples. Acceptable measures were those taken after $11 \mathrm{mo}$ of age. Because a variable number of measures were in the file for measures earlier than 12 mo of age and because not all females had the same number of measures, this procedure resulted in what seems to be randomized samples. Thus, sampling was of measures within cows, because nearly all cows were represented in each sample. The combined measures were also analyzed separately. Two other methods of sampling were also employed. Single measures of ovulation associated with the first eight acceptable measures after 11 mo of age were assigned to eight samples. In this case, fewer females were in the samples for measures at later ages. The other sampling involved summing of acceptable measures after 11 mo of age such that the first two, first three, and up to first eight measures were included in the sums. Except for constants, these sums correspond to averages of different numbers of measurements on the same female.

$\mathrm{N}$ ot enough measures of twinning were available to assign to samples. The basic data for twinning was for cows born after 1981. Three data sets were formed: the first contained measurements of number of calves born at the first parity (indicated by age at first calving of $2 \mathrm{yr}$, which corresponds generally to approximately 30 mo of age); the second contained measurements after the first parity; the third contained all measurements combined. A fourth analysis used twinning measures on all cows, including those born in 1981 and before.

Models. Models for measures of ovulation rate included 1) fixed effects of year-season of birth of female ( 17 for measures 1 to 5 , and 16 for measures 6 to 8); 2) four classes for age in months after $11 \mathrm{mo}$ corresponding to 12 to 13,14 to 15,16 to 17 , and $\geq 18$ mo; and 3) 12 calendar months of measurement. Fixed effects for measures of twinning rate were yearseason-age at calving subclasses, except first-parity measures were all at the same age.
Random effects in the models were additive genetic and residual (temporary environmental) in all cases. For samples with repeated measures, an animal permanent environmental effect was included. Analyses with the preceding random effects were also performed with dominance genetic effects included in the model.

The analyses were also performed with and without foundation group effects included in the model. The seven different foundation groups are described in Van Vleck et al. (1991b). The Westell procedure (Westell et al., 1988) could not be used because the vector of dominance effects would not have matched the vector containing group and additive breeding value effects. Thus, the fractions of inheritance from the seven groups were included as covariates in the model to account for foundation groups.

To simplify the computations, the inverse of one numerator relationship was used for all ovulation rate analyses; only animals with ovulation measures and their sires and dams were included. Five animals with inbreeding coefficients greater than zero, calculated from that file, were deleted, and the reduced matrix was used. For twinning analyses, the inverse of the numerator relationship matrix corresponding to all animals with either twinning or ovulation rate measures was used. To check this procedure, analyses with relationships computed only from cows born after 1981 with twinning measurements were also performed. The answers were the same for both cases. The dominance relationship matrix was computed by first inverting the inverse of the numerator relationship matrix computed with the rules of Henderson (1976) and Quass (1976). These matrices were of order 3,138; 3,487; and 2,275. Then the dominance relationship matrix was computed with the standard formula involving the relationships between sires and dams of pairs of animals (e.g., Henderson, 1984; Van Vleck, 1993). The third step was to invert that matrix. The numbers of non-zero elements were 4,506; 5,918; and 4,757, respectively. Only inverse elements with absolute value greater than .01 were used. The number of such elements was approximately the same as the number of non-zero elements in the corresponding dominance relationship matrix. Many elements in the dominance relationship matrices correspond to pairs of animals without records or were different from .25. Most information about dominance variance would likely come from full sib families. The numbers of full sibs and full sib families for the data sets are shown in Table 1.

Estimates of variance components by REML were obtained by application of the derivative-free algorithm (Smith and Graser, 1986; Graser et al., 1987) using programs of Meyer (1989) modified to use a sparse matrix algorithm (Boldman and Van Vleck, 1991) and the inverse elements of the dominance relationship matrix described previously. Convergence criterion was $1 \times 10^{-6}$ of the variance of twice the 
Table 1. Numbers of full sibs and numbers of full sib families by size for cows with ovulation and twinning rate measures

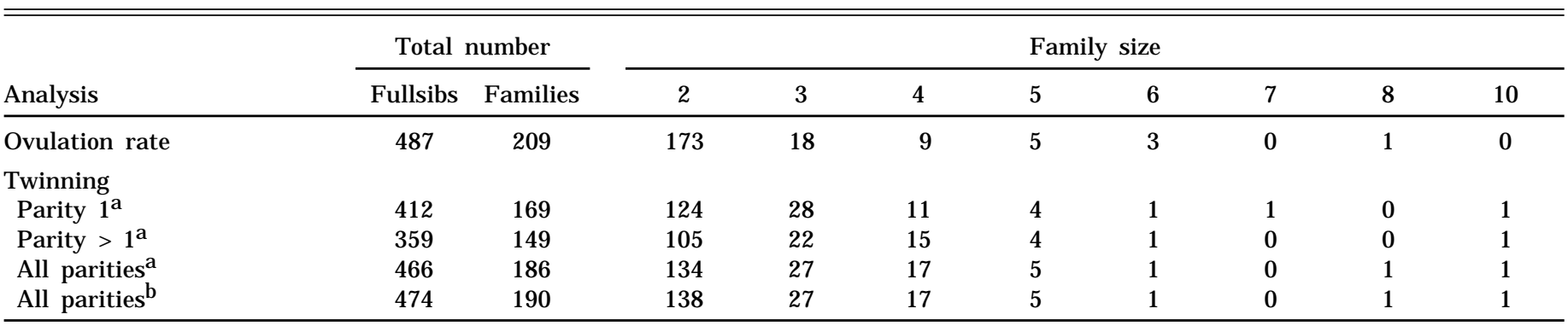

aFor cows born after 1981 .

$\mathrm{b}_{\mathrm{F}}$ or all cows in file.

logarithms of the likelihoods in the simplex. Restarts were performed to check for global convergence. In fact, in all cases original convergence appeared to be global.

\section{Results and Discussion}

Ovulation Rate. Characteristics of the data and models are shown in footnotes to Tables 2, 3, and 4. Table 2 lists estimates of components of variance as fractions of phenotypic variances for the repeated measures model. Estimates of dominance variance were uniformly near zero for models including or not including foundation group effects. As a result, the log likelihoods were essentially identical for models with and without dominance genetic effects. The models with foundation group effects resulted in smaller estimates of heritability and slightly larger estimates of variance due to permanent environmental effects. The logarithms of likelihood values were significantly $(\mathrm{P}<.05)$ different between the models with and without group effects. The estimates of heritability from sample to sample were quite consistent, but the estimates of permanent environmental variance were much more variable. The estimates from overall data were the same as those reported earlier (Van Vleck and Gregory, 1996) for the same data but with more complete numerator relationships.

Estimates for single sequential measures are in Table 3. The sequence corresponds roughly to increases in age of intervals of 2 or 3 wk. Heritability estimates were somewhat larger for later measures, which also had larger means. Three of the analyses had relatively large estimates for dominance variance, and five of the analyses had estimates of nearly zero. The differences in log likelihoods for the three samples were not significant $(P>.05)$. Only for measure 2 did the likelihood ratio test even approach significance. Relatively large estimates of dominance variance resulted in only slight decreases in additive heritability. As with analyses shown in Table 2, the inclusion of foundation group effects in the model resulted in reduced estimates of heritability, with the reduction

Table 2. Estimates for ovulation rate of variance components due to additive $\left(\mathrm{a}^{2}\right)$ and dominance $\left(\mathrm{d}^{2}\right)$ genetic and animal permanent environmental $\left(c^{2}\right)$ effects as proportions of phenotypic variance $\left(\sigma_{\mathrm{p}}^{2}\right)$ for Model I ignoring $\mathrm{d}^{2}$ and Model II including $\mathrm{d}^{2}$ with and without groups of origin as covariates for four samples and combined (ALL)

\begin{tabular}{|c|c|c|c|c|c|c|c|c|c|c|c|}
\hline \multirow[b]{3}{*}{ Sample } & \multicolumn{5}{|c|}{ Groups not in model ${ }^{a}$} & \multicolumn{5}{|c|}{ Groups in modela,b } & \multirow[b]{3}{*}{$\sigma_{\mathrm{p}}^{2}$} \\
\hline & \multicolumn{2}{|c|}{1} & \multicolumn{3}{|c|}{ II } & \multicolumn{2}{|c|}{1} & \multicolumn{3}{|c|}{ II } & \\
\hline & $a^{2}$ & $c^{2}$ & $a^{2}$ & $c^{2}$ & $d^{2}$ & $a^{2}$ & $c^{2}$ & $a^{2}$ & $c^{2}$ & $d^{2}$ & \\
\hline 1 & .070 & .016 & .070 & .016 & .001 & .056 & .027 & .055 & .016 & .012 & .127 \\
\hline 2 & .092 & .000 & .092 & .000 & .000 & .082 & .005 & .085 & .000 & .003 & .134 \\
\hline 3 & .103 & .024 & .103 & .024 & .000 & .090 & .035 & .090 & .035 & .000 & .132 \\
\hline 4 & .075 & .084 & .075 & .084 & .000 & .058 & .097 & .058 & .097 & .000 & .130 \\
\hline$A L L^{d}$ & .076 & .044 & .076 & .045 & .000 & .069 & .049 & .068 & .050 & .000 & .130 \\
\hline
\end{tabular}

aModel included fixed effect levels for year-season of birth (17), classes for age in mo >11 (4), and calendar month of measure (12).

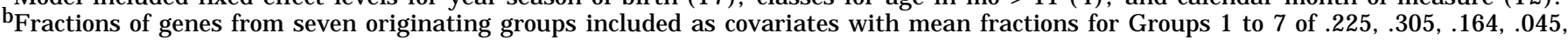
$.039, .150$ and .072 , respectively.

CNumber of animals averaged 2,278, and measures 4,802, with mean 1.15 .

d Number of animals was 2,317, and measures 19,209, with mean 1.15 . 
Table 3. Estimates of variance components due to additive $\left(\mathrm{a}^{2}\right)$ and dominance $\left(\mathrm{d}^{2}\right)$ genetic effects as proportions of phenotypic variance $\left(\sigma_{\mathrm{p}}^{2}\right)$ for Model I ignoring $\mathrm{d}^{2}$ and Model II including $\mathrm{d}^{2}$ with and without groups of origin as covariates for sequential measures of ovulation rate

\begin{tabular}{|c|c|c|c|c|c|c|c|c|}
\hline \multirow[b]{3}{*}{ Measure $^{c}$} & \multirow[b]{3}{*}{ Mean } & \multicolumn{3}{|c|}{ Groups not in model ${ }^{\mathrm{a}}$} & \multicolumn{3}{|c|}{ Groups in modela,b } & \multirow[b]{3}{*}{$\sigma_{\mathrm{p}}^{2}$} \\
\hline & & \multirow{2}{*}{$\frac{1}{a^{2}}$} & \multicolumn{2}{|c|}{ II } & \multirow{2}{*}{$\frac{1}{a^{2}}$} & \multicolumn{2}{|c|}{11} & \\
\hline & & & $a^{2}$ & $d^{2}$ & & $a^{2}$ & $d^{2}$ & \\
\hline 1 & 1.12 & .079 & .079 & .000 & .046 & .046 & .000 & .102 \\
\hline 2 & 1.14 & .069 & .059 & .257 & .060 & .047 & .290 & .122 \\
\hline 3 & 1.15 & .058 & .058 & .000 & .023 & .024 & .000 & .127 \\
\hline 4 & 1.17 & .094 & .094 & .000 & .071 & .071 & .000 & 140 \\
\hline 5 & 1.15 & .110 & .101 & .142 & .082 & .073 & .153 & .125 \\
\hline 6 & 1.17 & .149 & .145 & .104 & .141 & .137 & .111 & .140 \\
\hline 7 & 1.16 & .085 & .085 & .000 & .067 & .067 & .000 & .139 \\
\hline 8 & 1.17 & .108 & .108 & .000 & .100 & .100 & .000 & .144 \\
\hline Mean & - & .094 & .091 & .063 & .074 & .071 & .069 & .130 \\
\hline
\end{tabular}

aModel included fixed effect levels for year-season of birth ( 17 for measures 1 to 5 and 16 for measures 6 to 8 ), classes for age in mo $>11$ (4), and calendar month of measure (12).

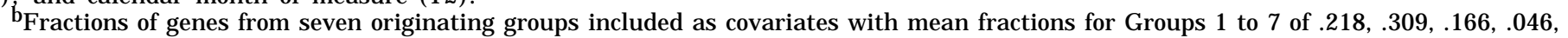
$.039, .151$ and .072 for measure 1 .

CNumber of animals ranged from 2,317 for measure 1 to 1,793 for measure 8.

more variable than with the analyses of repeated measures on the same female. Of the log likelihoods for the groups and no groups models, only for measure 2 was the likelihood ratio test significant $(P<.05)$.

Table 4 lists estimates for sequential sums of measures: first two, first three, and up to first eight measures. Previously discussed patterns are apparent. Likelihood ratio tests between models with and without dominance variance were not significant; in fact, the log likelihoods were nearly identical except for sum of first two measures that had a difference of only .66. The likelihood ratio tests between group and no group models increased with number of measures in the sum and reached significance for sums of six, seven, and eight measures. The most important result in Table 4 is the increase in heritability with increasing number of measures in the sum (or average) as expected from theory. In fact, the increase matches very closely that expected when additive genetic and permanent environmental correlations are unity between all pairs of measures. This result confirms the theoretical basis for using measures of ovulation rate to select for twinning rate (Echternkamp et al., 1990; Van Vleck et al., 1991a,b).

Twinning Rate. Means and numbers of cows and of measures for the analyses are in Table 5. Estimates of variance components are in Table 6 . These estimates suggest the need for more data to determine whether

Table 4. Estimates of variance components due to additive $\left(\mathrm{a}^{2}\right)$ and dominance $\left(\mathrm{d}^{2}\right)$ genetic effects as proportions of phenotypic variance $\left(\sigma_{\mathrm{p}}^{2}\right)$ for Model I ignoring $\mathrm{d}^{2}$ and Model II including $\mathrm{d}^{2}$ with and without groups of origin as covariates for sums of consecutive measures of ovulation rate

\begin{tabular}{|c|c|c|c|c|c|c|c|c|c|}
\hline \multirow[b]{3}{*}{ Sum $^{C}$ of } & \multirow[b]{3}{*}{ Mean } & \multicolumn{3}{|c|}{ Groups not in model ${ }^{a}$} & \multirow[b]{3}{*}{$\sigma_{\mathrm{p}}^{2}$} & \multicolumn{3}{|c|}{ Groups in model ${ }^{a, b}$} & \multirow[b]{3}{*}{$\sigma_{\mathrm{p}}^{2}$} \\
\hline & & \multirow{2}{*}{$\frac{\mathrm{l}}{\mathrm{a}^{2}}$} & \multicolumn{2}{|c|}{ II } & & \multirow{2}{*}{$\frac{1}{a^{2}}$} & \multicolumn{2}{|c|}{ II } & \\
\hline & & & $a^{2}$ & $d^{2}$ & & & $a^{2}$ & $d^{2}$ & \\
\hline 2 & 2.26 & .131 & .124 & .185 & .256 & .108 & .099 & .199 & .254 \\
\hline 3 & 3.41 & .165 & .162 & .075 & .438 & .135 & .132 & .066 & .434 \\
\hline 4 & 4.57 & .206 & .205 & .000 & .701 & .174 & .174 & .000 & .694 \\
\hline 5 & 5.73 & .230 & .227 & .039 & .968 & .198 & .196 & .046 & .959 \\
\hline 6 & 6.90 & .286 & .285 & .000 & 1.253 & .260 & .260 & .007 & 1.241 \\
\hline 7 & 8.07 & .297 & .297 & .000 & 1.611 & .269 & .269 & .000 & 1.594 \\
\hline 8 & 9.26 & .316 & .316 & .000 & 1.978 & .289 & .287 & .000 & 1.955 \\
\hline
\end{tabular}

aModel included fixed effect levels for year-season of birth ( 17 for sums of first 5 and 16 for sums of 8 measures), classes for age in mo $>11$ (4), and calendar month of measure after 11 mo (12).

Fractions of genes from seven originating groups included as covariates with mean fractions for Groups 1 to 7 of .241, .300, .158, .043, $.038, .147$ and .072 for sum of 8 measures.

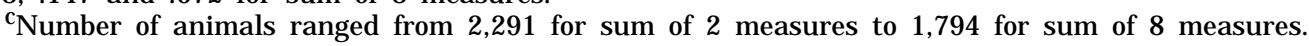


Table 5. Means, numbers of animals with measures, number of measures and number of year-season-age at calving classes for four analyses of twinning rate depending on year of birth and parity

\begin{tabular}{|c|c|c|c|c|}
\hline \multirow[b]{2}{*}{ Analysis } & \multirow[b]{2}{*}{ Mean } & \multicolumn{3}{|c|}{ Number } \\
\hline & & Animals & Measures & $\begin{array}{l}\text { Year-season } \\
\text { age classes }\end{array}$ \\
\hline First parity, born >1981 & 1.15 & 1,522 & 1,522 & 20 \\
\hline After first parity, born $>1981$ & 1.20 & 1,311 & 3,571 & 48 \\
\hline All parities, born >1981 & 1.19 & 1,704 & 5,100 & 68 \\
\hline All parities, all cows & 1.17 & 2,081 & 6,397 & 96 \\
\hline
\end{tabular}

sampling variances are responsible for the different patterns between first parity and later parity measures and between ovulation rate and twinning rate measures. The first-parity estimates are relatively large for both additive and dominance genetic variance. The likelihood ratio tests were not significant ( $P$ $>.05$ ) between models with and without dominance effects. Including foundation group effects in the model reduced slightly estimates of additive and dominance genetic variance. Likelihood ratio tests between group and no group models were significant $(\mathrm{P}<.05)$.

Estimates for later parities were much smaller for additive and especially for dominance genetic variance than for first parities. When dominance effects were dropped from the model, most of that variation became associated with the permanent environmental and additive genetic effects. Tests between models with and without dominance effects were not significant. Likelihood ratio tests of differences between group and no group models were significant $(P<.05)$.

The estimates when all parities for cows born after 1981 were included follow a pattern similar to those for later parities as do estimates for the whole data file, except that estimates of heritability from the whole data file are smaller and estimates of permanent environmental (or dominance) effects are larger. There is evidence that embryo survival, which is the

Table 6. Estimates for twinning rate of variance components due to additive $\left(\mathrm{a}^{2}\right)$, dominance $\left(\mathrm{d}^{2}\right)$ genetic, and animal permanent environmental $\left(\mathrm{c}^{2}\right)$ effects as proportions of phenotypic variance $\left(\sigma_{\mathrm{p}}^{2}\right)$ for Model I ignoring $\mathrm{d}^{2}$ and Model II including $\mathrm{d}^{2}$ with and without groups of origin as covariates for four data sets determined by parity of measurement and year born

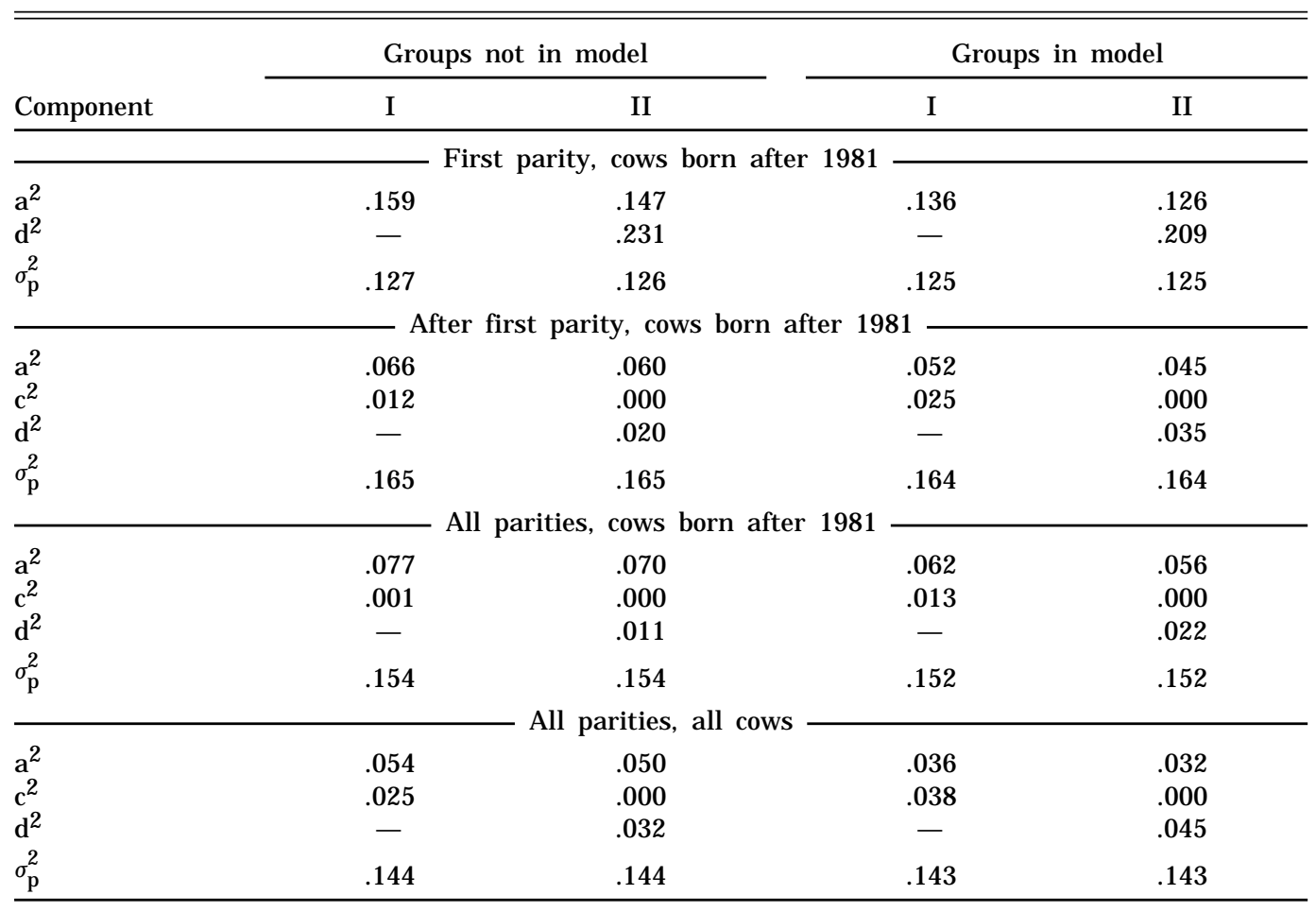


main difference between ovulation and twinning rates, shows heterosis that should result in dominance variance in a composite population such as the twinning population. Cundiff et al. (1974) presented results showing an increase in percentage calf crop weaned of 6.4 for crossbred compared with straightbred cows in a three-breed diallel crossing experiment. This difference was the result of higher $(\mathrm{P}<.01)$ pregnancy rates and first-service conception rates in the crossbred compared with their straightbred half-sibs of the Hereford, Angus, and Shorthorn breeds.

\section{Conclusions}

These analyses suggest that dominance effects are not important for ovulation rate. For twinning rate, which is basically the product of ovulation rate, conception rate, and embryo survival, the results are inconsistent. Why should dominance effects be important for first-parity twinning and relatively unimportant for later parities? Why would heritability for firstparity twinning be much greater than for later parities? And why would dominance variance also be much greater for first- than later-parity twinning rate? A reviewer suggested that the results may indicate immunological reactions between dam and fetus. Thus, the conclusion is that these analyses of additive and dominance effects on twinning rate for first, subsequent, and all parities have developed more questions than answers in spite of having data with many full sib pairs.

\section{Implications}

The results indicate that dominance effects are not important for ovulation rate. Thus, crosses among independent lines selected for ovulation rate would not be expected to express heterosis for ovulation rate. The results for twinning rate, which is a product of ovulation rate, conception rate, and survival rate, are ambiguous, although the analysis of first-parity twinning rates suggests there may be dominance effects involved that could be due to dominance for conception rate and(or) embryo survival. If that is true, crosses of lines selected independently for twinning rate would be expected to express heterosis for twinning rate.

\section{Literature Cited}

Boldman, K. G., and L. D. Van Vleck. 1991. Derivative-free restricted maximum likelihood estimation in animal models with a sparse matrix solver. J. Dairy Sci. 74:4337.

Chang, H. L., R. L. Fernando, and D. Gianola. 1990. An evaluation of maximum likelihood estimates of non-additive genetic variances. In: W. G. Hill, R. Thompson, and J . A. Wooliams (E d.) Proc. 4th World Congr. Genet. Appl. Livest. Prod. 13:437.

Cundiff, L. V., K. E. Gregory, and R. M. Koch. 1974. Effects of heterosis on reproduction in Hereford, Angus, and Shorthorn cattle. J. Anim. Sci. 38:711.

Echternkamp, S. E., K. E. Gregory, G. E. Dickerson, L. V. Cundiff, R. M. Koch, and L. D. Van Vleck. 1990. Twinning in cattle: II. Genetic and environmental effects on ovulation rate in puberal heifers and postpartum cows and the effects on ovulation rate on embryonic survival. J. Anim. Sci. 68:1877.

Graser, H.-U., S. P. Smith, and B. Tier. 1987. A derivative-free approach for estimating variance components in animal models by restricted maximum likelihood. J. Anim. Sci. 64:1362.

Gregory, K. E., S. E. Echternkamp, G. E. Dickerson, L. V. Cundiff, R. M. Koch, and L. D. Van Vleck. 1990a. Twinning in cattle: I. Foundation animals and genetic and environmental effects on twinning rate. J. Anim. Sci. 68:1867.

Gregory, K. E., S. E. Echternkamp, G. E. Dickerson, L. V. Cundiff, R. M. Koch, and L. D. Van Vleck. 1990b. Twinning in cattle: III. Effects of twinning on dystocia, reproductive traits, calf survival, calf growth and cow productivity. J . Anim. Sci. 68:3133.

Henderson, C. R. 1976. A simple method for computing the inverse of a numerator relationship matrix used in prediction of breeding values. Biometrics 32:69.

Henderson, C. R. 1984. Linear models in animal breeding. Univ. Guelph Press, Guelph, Ontario, Canada.

Meyer, K. 1989. Restricted maximum likelihood to estimate variance components for animal models with several random effects using a derivative-free algorithm. Genet. Sel. Evol. 21:317.

Quaas, R. L. 1976. Computing the diagonal elements and inverse of a large numerator relationship matrix. Biometrics 32:949.

Rodríguez-Almeida, F. A., L. D. Van Vleck, R. L. Willham, and S. L. Northcutt. 1995. Estimation of non-additive genetic variances in three synthetic lines of beef cattle using an animal model. J . Anim. Sci. 73:1002.

Smith, S. P., and H.-U. Graser. 1986. Estimating variance components in a class of mixed models by restricted maximum likelihood. J. Dairy Sci. 69:1156.

Van Vleck, L. D. 1993. Selection Index and Introduction to Mixed Model Methods. CRC Press, Boca Raton, FL.

Van Vleck, L. D., and K. E. Gregory. 1996. Genetic trend and environmental effects in a population selected for twinning. J . Anim. Sci. 74:522.

Van Vleck, L. D., K. E. Gregory, and S. E. Echternkamp. 1991a. Ovulation rate and twinning rate in cattle: Heritabilities and genetic correlation. J. Anim. Sci. 69:3213.

Van Vleck, L. D., K. E. Gregory, and S. E. Echternkamp. 1991b. Prediction of breeding values for twinning rate and ovulation rate with a multiple trait, repeated records animal model. J. Anim. Sci. 69:3959.

Westell, R. A., R. L. Quaas, and L. D. Van Vleck. Genetic groups in an animal model. 1988. J. Dairy Sci. 71:1310. 